\title{
ANALISIS PENGENDALIAN MUTU BAHAN BAKU UTAMA SUSU KAMBING BUBUK DI BUMIKU HIJAU YOGYAKARTA
}

\author{
ANALYSIS OF QUALITY CONTROL OF MAIN RAW MATERIAL OF \\ GOAT MILK POWDER IN BUMIKU HIJAU YOGYAKARTA
}

\author{
*Yohana Agustina, Jangkung Handoyo Mulyo, dan Lestari Rahayu Waluyati \\ Program Studi Magister Magister Manajemen Agribisnis, Fakultas Pertanian, \\ Universitas Gadjah Mada
}

Submitted: 26-12-2018; Revised: 30-07-2019; Accepted: 01-08-2019

\begin{abstract}
Quality control of a product is one of the main factors in the industrial world. One of them is in the food processing industry. Bumiku Hijau Yogyakarta is one of the goat milk powder producers in Yogyakarta. This study was conducted to determine the quality control process of raw materials, and to identify dominant causative factors on raw materials quality failures of goat milk powder in Bumiku Hijau Yogyakarta. The data used was total of raw materials failures from January to May 2018. Data analysis techniques use statistical quality control, there is $p$-chart and cause-effect diagram to identify the causes of raw materials failures. The result of p-chart analysis, indicates that 6 points exceed the upper control limit from January to March 2018. Total failure of raw materials from January to March 2018 was 18 liters of pure goat milk. The most common type of raw materials failure causes are the color of pure goat milk is muddy and the aroma is not fresh. The result of identification on dominant causative factors of raw materials failures using cause-effect diagram shows that the factors causing raw materials failures are farmers (man), production equipment (machine), and environment. The recommendation could be given to the company are carried out coaching and training on good goat milking technique and post handling of goat milking process to all milkmaid, also implementing reward and punishment system to partner farms.
\end{abstract}

Keywords: Cause-Effect Diagram; Goat Milk Powder; P-chart; Quality Control.

\begin{abstract}
ABSTRAK
Pengendalian mutu suatu produk merupakan salah satu faktor utama dalam dunia perindustrian. Salah satunya pada industri pengolahan pangan. Bumiku Hijau merupakan salah satu produsen susu kambing bubuk di Yogyakarta. Tujuan penelitian ini adalah untuk mengetahui proses pengendalian mutu bahan baku, dan mengidentifikasi faktor-faktor penyebab dominan dalam kegagalan mutu bahan baku susu kambing bubuk di Bumiku Hijau Yogyakarta. Data yang digunakan adalah jumlah kegagalan bahan baku selama Januari sampai dengan Mei 2018. Teknik analisis data menggunakan statistical quality control, yaitu peta kendali $\mathrm{p}(p$-chart) dan diagram sebab-akibat untuk mengidentifikasi penyebab kegagalan bahan baku. Hasil dari analisis peta kendali $\mathrm{p}$ ( $p$-chart), menunjukkan bahwa terdapat 6 titik yang melewati batas atas kendali statistik selama Januari sampai dengan Maret 2018. Total kegagalan bahan baku (reject) selama Januari sampai dengan Maret 2018 adalah 18 liter susu
\end{abstract}

*Corresponding author: yohana.umm@gmail.com

Copyright $\odot 2020$ THE AUTHOR(S). This article is distributed under a Creative Commons Attribution-Share Alike 4.0 International license. Jurnal Teknosains is published by the Graduate School of Universitas Gadjah Mada. 
kambing murni. Jenis penyebab kegagalan bahan baku yang paling banyak adalah karena warna susu kambing keruh dan aromanya tidak segar. Hasil identifikasi faktor penyebab kegagalan bahan baku dominan dengan menggunakan diagram sebab akibat menunjukkan bahwa faktor-faktor penyebab kegagalan bahan baku antara lain adalah peternak, peralatan produksi, dan lingkungan. Saran yang dapat diberikan kepada perusahaan adalah dengan melaksanakan pembinaan dan pelatihan tentang teknik pemerahan susu kambing yang benar dan penanganan pascaproses pemerahan susu kambing kepada seluruh karyawan pemerah, serta menerapkan sistem reward and punishment kepada peternakan mitra.

Kata Kunci:DiagramSebab-Akibat;Pengendalian Mutu; Peta Kendali P; Susu Kambing Bubuk.

\section{PENGANTAR}

Susu merupakan salah satu bahan pangan yang baik bagi manusia karena kandungan gizinya yang beragam, tetapi susu juga merupakan salah satu bahan pangan yang mudah rusak. Kandungan gizi dan aktivitas air yang tinggi pada susu menjadi tempat perkembangbiakan yang baik bagi mikroba, sehingga produk susu rentan akan kontaminasi bakteri dan mikroba. Dirjen Industri Agro, Kementerian Perindustrian RI (2015), menetapkan Industri Pengolahan Susu di Indonesia sebagai salah satu industri yang akan terus diprioritaskan perkembangannya.

Sumber konsumsi susu segar yang saat ini mulai digemari oleh masyarakat Indonesia selain susu sapi adalah susu kambing segar. Produk olahan susu kambing segar yang telah beredar luas di masyarakat saat ini adalah permen susu, kefir, dan susu kambing bubuk (Danarwati, 2018). Pengolahan susu kambing segar menjadi susu kambing bubuk merupakan salah satu upaya untuk memperpanjang masa simpan dan menekan perkembangbiakan mikroba (Cyrilla, dkk., 2015). Salah satu industri pengolahan pangan skala mikro yang memproduksi susu kambing bubuk di Yogyakarta adalah Bumiku Hijau. Bumiku Hijau merupakan produsen yang mengolah susu kambing murni menjadi berbagai macam produk, antara lain yaitu yogurt, es krim susu kambing, kefir, dan susu kambing bubuk. Susu kambing bubuk Bumiku Hijau merupakan salah satu produk bergizi yang saat ini telah beredar di pasar dan digemari oleh masyarakat luas.

Upaya memasarkan produk secara luas dan meningkatkan skala usaha, perusahaan harus mampu memenuhi kepuasan pelanggan. Salah satu upaya perusahaan dalam memenuhi kepuasan pelanggan adalah dengan menjaga mutu produk yang dihasilkan. Permasalahan yang sering dihadapi oleh perusahaan selama proses produksi berlangsung adalah adanya produk gagal atau rusak (reject). Upaya perbaikan mutu secara berkelanjutan diperlukan untuk mengatasi masalah tersebut, sehingga mutu produk dapat terjaga dengan baik (Hariyanto, 2017). Salah satu upaya perbaikan mutu secara berkelanjutan dapat dilakukan dengan menggunakan pengendalian mutu statistik. Pengendalian mutu secara statistik atau sering disebut dengan Statistical Quality Control (SQC) merupakan salah satu alat manajemen yang sering digunakan pada industri manufaktur untuk meningkatkan mutu produk dan produktivitas pekerja (Oguntunde, dkk., 2015). Penerapan teknik pengendalian mutu secara statistik telah dilakukan oleh beberapa peneliti sebelumnya. Zare (2016), menyatakan bahwa dalam proses pengendalian mutu pada beberapa atribut pelayanan pada industri jasa (restoran) dengan menggunakan teknik Statistical Process Control (SPC), secara keseluruhan proses dalam kendali statistik.

Berdasarkan pemaparan di atas, maka perlu dilakukan penelitian mengenai standar pengendalian mutu susu kambing bubuk di Bumiku Hijau. Penelitian ini bertujuan untuk mengetahui pengendalian mutu bahan baku dengan menggunakan peta kendali $p$ dan diagram sebab-akibat untuk mengidentifikasi faktor-faktor penyebab dominan kegagalan bahan baku utama di Bumiku Hijau Yogyakarta.

\section{Metode}

Penelitian ini dilakukan di Bumiku Hijau, salah satu produsen susu kambing bubuk di Yogyakarta. Desain penelitian 
yang digunakan dalam penelitian ini adalah pendekatan kuantitatif yang berbentuk deskriptif, yaitu dengan cara menjelaskan dan menguraikan pelaksanaan pengendalian mutu bahan baku utama pembuatan susu kambing bubuk, dan faktor-faktor dominan apa saja yang menyebabkan kegagalan mutu bahan baku susu kambing bubuk. Pengolahan data dilakukan selama lima bulan, yaitu dari bulan Januari sampai dengan Mei 2018.

Objek dalam penelitian ini adalah bahan baku utama dalam pembuatan susu kambing bubuk, yaitu susu kambing murni yang disuplai dari peternak binaan Bumiku Hijau. Mutu bahan baku utama diuji secara organoleptik, dimana atribut pengujiannya meliputi warna, rasa, bau (aroma), dan tekstur. Jumlah bahan baku yang diamati per harinya adalah 60 liter susu kambing murni. Sumber data dalam penelitian ini adalah primer, dimana diperoleh dari hasil observasi harian dan wawancara dengan kepala bagian penjualan dan pengolahan susu kambing murni dan bubuk, staf bagian laboratorium penerimaan susu kambing murni serta staf bagian pengolahan susu kambing bubuk.

Teknik analisis data dilakukan dengan menggunakan teknik statistical quality control, di mana langkah-langkahnya adalah sebagai berikut: (1) mengumpulkan data jumlah bahan baku yang diperiksa dan bahan baku rusak; (2) membuat peta kendali $p$ ( $p$-chart); (3) membuat diagram sebab-akibat faktor-faktor penyebab kegagalan mutu bahan baku (Haryono, 2015).

Penelitian ini menggunakan peta kendali $p$ dengan batas kendali tiga sigma karena batas kendali tersebut sangat bagus dalam mendeskripsikan proses saat data bervariasi (Djekic, dkk., 2014). Tahap - tahap pembuatan peta kendali $p$ ( $p$-chart) adalah sebagai berikut: a. Mengumpulkan data jumlah bahan baku yang disuplai peternak mitra Bumiku Hijau sebagai bahan baku pembuatan susu kambing bubuk dan data jumlah bahan baku yang cacat atau tidak memenuhi standar perusahaan selama Januari sampai dengan Mei 2018. Tercatat sebanyak 127 hari pengujian organoleptik pada susu kambing murni. b. Menghitung proporsi kegagalan (Montgomery, 2009) :

$$
p i=\frac{x}{n} \text {. }
$$

Keterangan :

pi : Proporsi kegagalan dalam setiap pengujian bahan baku (susu kambing murni) per hari

$x \quad$ : Banyaknya bahan baku (susu kambing murni) yang gagal per hari pengujian

n : Jumlah bahan baku (susu kambing murni) yang diuji per hari

c. Menghitung garis pusat atau Central Line $(C L)$ :

$$
\bar{p}=\frac{\sum_{i=1}^{g} p i}{g}
$$

Keterangan :

$\bar{p} \quad$ : Garis pusat peta kendali proporsi kegagalan bahan baku

pi : Total proporsi kegagalan bahan baku selama pengujian organoleptik per satu bulan

9 : Total bahan baku yang diuji selama satu bulan (liter)

d. Menghitung batas kendali atas atau Upper Control Limit (UCL) :

$$
\mathrm{UCL}=\bar{p}+3 \sqrt{\frac{\bar{p}(1-\bar{p})}{n}}
$$

Keterangan :

$\bar{p} \quad$ : Garis pusat peta kendali proporsi kegagalan bahan baku

$n \quad$ : Jumlah bahan baku yang diuji per hari (liter)

e. Menghitung batas kendali bawah atau Lower Control Limit (LCL) :

$$
\mathrm{LCL}=\bar{p}-3 \sqrt{\frac{\bar{p}(1-\bar{p})}{n}}
$$

Keterangan :

$\bar{p} \quad$ : Garis pusat peta kendali proporsi kegagalan bahan baku

$n \quad$ : Jumlah bahan baku yang diuji per hari (liter) 
Tahap berikutnya adalah mencari faktor penyebab dominan kegagalan produk dengan diagram sebab-akibat atau sering disebut dengan diagram tulang ikan. Faktor-faktor penyebab kegagalan bahan baku ditentukan melalui identifikasi jenis-jenis kegagalan. Dari hasil identifikasi jenis-jenis kegagalan tersebut dirumuskan beberapa rekomendasi upaya perbaikan, sehingga menghasilkan solusi untuk memperbaiki dan memperkecil terjadinya masalah yang sama dikemudian hari (Jha, 2013).

Penyusunan diagram sebab akibat untuk mengidentifikasi jenis-jenis kegagalan mutu bahan baku utama di Bumiku Hijau Yogyakarta terdapat beberapa tahapan. Tahapan tersebut antara lain meliputi: proses identifikasi masalah utama, meletakkan masalah utama di sebelah kanan diagram atau yang paling dekat dengan "kepala ikan", mengidentifikasi penyebab utama sebagai sumber penyebab penyimpangan dan meletakkannya pada diagram masalah utama, mengidentifikasi penyebab lainnya (pendukung) pada diagram masalah utama, dan tahap terakhir adalah mengevaluasi diagram tersebut untuk menentukan solusi dari permasalahan utama (Bose, 2012).

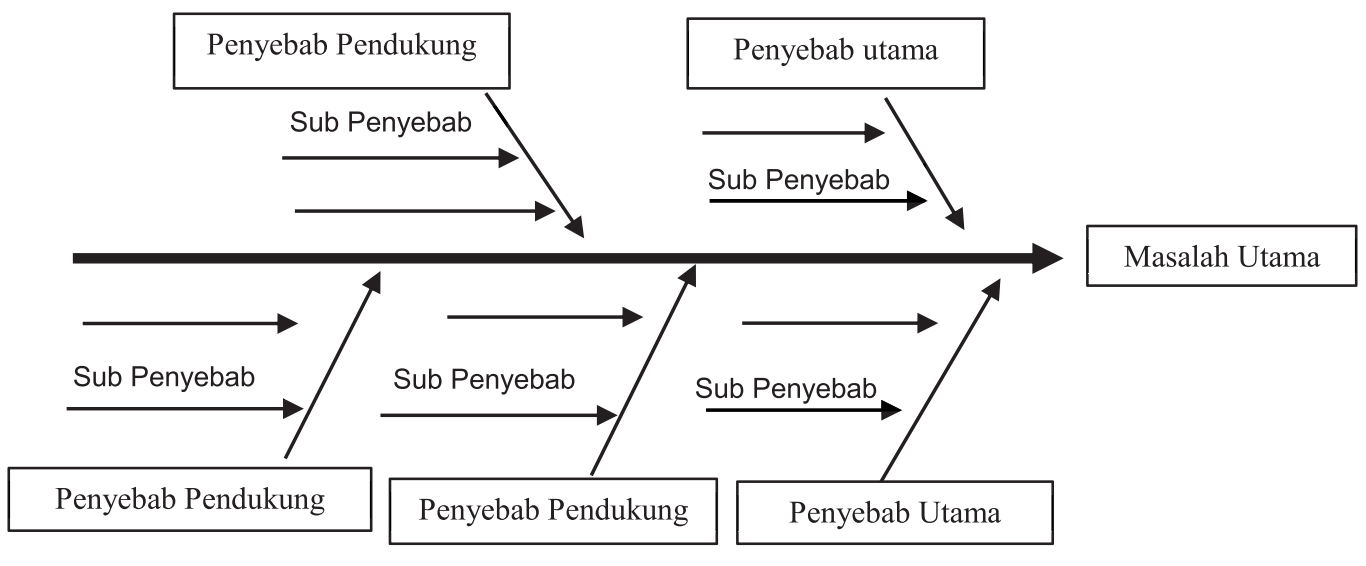

Gambar 1

Identifikasi Faktor Dominan Kegagalan Produk dengan Diagram Sebab Akibat Sumber: Bose, 2012

Dalam menentukan kemungkinankemungkinan faktor penyebab masalah kegagalan suatu produk akan dihubungkan pada berbagai rujukan teori yang ada meliputi: faktor manusia (man), alat dan mesin produksi (machine), metode saat proses produksi (method), bahan-bahan baku yang digunakan untuk proses produksi (materials), dan faktor lingkungan kerja (environment). Panah dari sumber penyebab yang paling mendekati "kepala ikan" merupakan faktor penyebab utama yang menimbulkan masalah kegagalan suatu produk (Bose, 2012).

\section{HASIL DAN PEMBAHASAN Proses Pengendalian Mutu Bahan Baku Utama}

Pengendalian mutu merupakan kegiatan yang dilakukan untuk menjamin bahwa proses yang sedang berlangsung akan menghasilkan produk sesuai dengan tujuan yang ditetapkan perusahaan. Kegiatan utama dalam pengendalian mutu suatu produk adalah mengevaluasi dan membandingkan kinerja proses dengan tujuan yang telah ditetapkan (Tamime, 2009).

Menurut Haryono (2015), terdapat beberapa hal yang perlu diperhatikan dalam kegiatan pengendalian mutu suatu produk yaitu meliputi: bahan baku, proses produksi, produk jadi, pengemasan, dan pengangkutan. Pengendalian mutu pada bahan baku perlu diamati sejak membuat rencana pembelian bahan baku, penerimaan bahan baku di gudang, penyimpanan bahan baku di gudang, sampai dengan bahan baku digunakan untuk proses produksi. 
Proses pengendalian mutu pada susu kambing murni Bumiku Hijau Yogyakarta dilakukan dengan uji organoleptik. Tujuan dari pengujian organoleptik tersebut adalah untuk mengetahui apakah terdapat masalah penyimpangan pada susu kambing murni. Pengujian organoleptik lebih banyak menggunakan indra manusia, sehingga dapat diketahui langsung apabila terjadi penyimpangan. Pelaksanaan pengujian organoleptik pada susu kambing murni dilakukan oleh dua orang staf ahli bagian laboratorium penerimaan susu di kantor pusat Bumiku Hijau Yogyakarta.

Secara garis besar alur prosedur pengujian organoleptik susu kambing murni di Bumiku Hijau Yogyakarta adalah sebagai berikut:

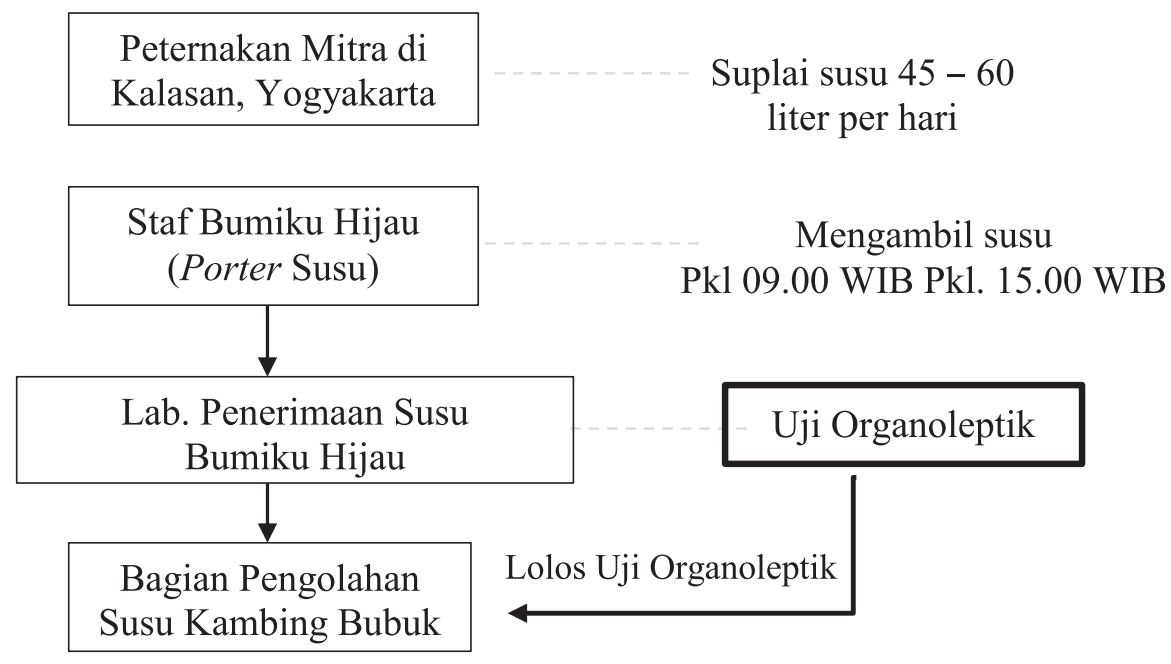

Gambar 2

Alur Pengujian Susu Kambing Murni di Bumiku Hijau Yogyakarta Sumber: Manajemen Bumiku Hijau, 2018

Atribut dalam pengujian organoleptik terhadap bahan baku susu kambing bubuk meliputi bau (aroma), rasa, warna, dan tekstur.
Adapun standar mutu bahan baku pembuatan susu kambing bubuk yang diterapkan oleh Bumiku Hijau pada tabel 1.

Tabel 1

Syarat Mutu Bahan Baku Utama Susu Kambing Murni Bumiku Hijau

\begin{tabular}{l|l|l|l}
\hline No & \multicolumn{1}{|c|}{ Kriteria Uji } & \multicolumn{1}{|c}{ Deskripsi } & \multicolumn{1}{|c}{ Spesifikasi } \\
\hline 1. & Aroma (Bau) & Berbau skim kuat; Aroma khas kambing (agak prengus) & Normal \\
\hline 2. & Rasa & Gurih sedikit manis & Normal \\
\hline 3. & Warna & Putih & Normal \\
\hline 4. & Tekstur & Tidak pecah; tidak menggumpal & Normal \\
\hline
\end{tabular}

Sumber: Manajemen Bumiku Hijau, 2018.

Bahan baku utama memegang peranan penting dalam suatu proses produksi karena baik buruknya bahan baku akan mempengaruhi mutu produk akhir. Sampai saat ini Indonesia belum mempunyai standar khusus terkait parameter mutu susu kambing murni. Parameter mutu susu kambing murni di Indonesia masih mengacu pada SNI syarat mutu susu sapi segar (BSN, 2011). Terjadinya masalah kegagalan mutu pada susu kambing murni umumnya sering disebabkan oleh beberapa faktor, antara lain adalah terjadinya kontaminasi saat proses pemerahan susu kambing, dan lamanya masa simpan untuk diproses lebih lanjut setelah proses pemerahan susu kambing. 
Masalah kegagalan mutu tersebut akan mengakibatkan terjadinya perubahan derajat keasaman $(\mathrm{pH})$ pada susu kambing murni, sehingga susu kambing murni tidak dapat diproses lebih lanjut karena akan berpengaruh pada mutu produk akhir. Selama proses pengujian organoleptik pada susu kambing murni di Bumiku Hijau, diperoleh hasil berupa data jumlah bahan baku yang di uji dan jumlah kegagalan bahan baku selama Januari sampai dengan Mei 2018.

Tabel 2

Jumlah Kegagalan Bahan Baku Utama Susu Kambing Bubuk Bumiku Hijau, Januari - Mei 2018

\begin{tabular}{l|l|l|l}
\hline \multicolumn{1}{c|}{ Bulan } & \multicolumn{1}{|c|}{$\begin{array}{c}\text { Total Suplai Bahan Baku } \\
\text { (Liter) }\end{array}$} & $\begin{array}{c}\text { Jumlah Bahan Baku Reject (pi) } \\
\text { (Liter) }\end{array}$ & $\begin{array}{c}\text { Proporsi Kegagalan } \\
\text { Bahan Baku (pi) }\end{array}$ \\
\hline Januari & 1.560 & 8 & 0,13 \\
\hline Februari & 1.380 & 7 & 0,11 \\
\hline Maret & 1.620 & 3 & 0,05 \\
\hline April & 1.500 & 0 & 0,00 \\
\hline Mei & 1.560 & 0 & 0,00 \\
\hline Total & $\mathbf{7 . 6 2 0}$ & $\mathbf{1 8}$ & $\mathbf{0 , 2 9}$ \\
\hline
\end{tabular}

Sumber: Data diolah primer, 2018

Jumlah bahan baku yang diterima dari peternak mitra Bumiku Hijau Yogyakarta dan di uji perhari adalah sebanyak 60 liter susu kambing murni. Jumlah penerimaan susu kambing murni perharinya bergantung pada permintaan pasar dan sisa susu kambing murni yang digunakan untuk produksi pada hari sebelumnya. Jumlah hari pengujian organoleptik pada susu kambing murni di Bumiku Hijau tercatat sebanyak 127 hari pengujian. Total bahan baku yang di uji selama bulan Januari sampai dengan Mei 2018 adalah 7.620 liter susu kambing murni.

Berdasarkan tabel di atas dapat diketahui bahwa dari 7.620 liter susu kambing murni yang diuji selama 127 hari pengujian terdapat 18 liter susu kambing murni yang mengalami kegagalan mutu. Selama bulan Januari sampai dengan Maret 2018 sering terjadi masalah kegagalan mutu pada susu kambing murni dikarenakan faktor internal di peternakan mitra Bumiku Hijau Yogyakarta. Jenis penyebab umum yang mengakibatkan masalah pada kegagalan mutu susu kambing murni di Bumiku Hijau adalah warna susu keruh dan aroma susu kambing murni sudah tidak segar (basi).

Manajemen Bumiku Hijau melakukan tindakan evaluasi dan pembinaan terhadap peternakan mitra untuk meminimalisir kegagalan mutu pada susu kambing murni. Tahap selanjutnya setelah mengumpulkan data terkait informasi jumlah susu kambing murni yang gagal adalah menentukan batas-batas kendali dengan peta kendali atribut $p$-chart $3 \sigma$ selama bulan Januari sampai dengan Mei 2018 yang tersaji pada tabel 3 .

\section{Tabel 3}

Batas - Batas Kendali Kegagalan Bahan Baku, Januari - Mei 2018

\begin{tabular}{l|l|l}
\hline \multicolumn{1}{c|}{ Uraian } & & \multicolumn{1}{c}{ Total } \\
\hline $\begin{array}{l}\text { Bahan baku yang di uji } \\
\text { (liter) }\end{array}$ & 7.620 \\
\hline $\begin{array}{l}\text { Bahan baku yang reject } \\
\text { (liter) }\end{array}$ & 18 \\
\hline Garis Pusat Peta Kendali $p$ & CL & 0,00 \\
\hline Batas Kendali Atas & UCL & 0,02 \\
\hline Batas Kendali Bawah & LCL & 0,00 \\
\hline
\end{tabular}

Sumber: Data diolah primer, 2018

Proses analisis dari hasil tabulasi data uji organoleptik bahan baku utama sampai dengan penimbangan ulang produk akhir dalam penelitian ini menggunakan pendekatan Statistical Quality Control (SQC). Dalam 
penelitian ini tidak menggunakan semua alat (tools) yang terdapat dalam statistical quality control, hanya digunakan jenis alat yang sesuai dengan kondisi permasalahan yang akan dipecahkan yaitu peta kendali (control chart) berupa grafik garis yang menampilkan batas maksimum dan batas minimum untuk menyatakan apakah objek yang diamati berada dalam batas pengendalian statistik atau tidak.

Langkah berikutnya setelah ditetapkan batas-batas kendali kegagalan bahan baku dengan menggunakan peta kendali $p$ selama Januari sampai dengan Mei 2018 adalah membuat grafik peta kendali $p$ seperti yang tersaji pada gambar 3 .

\section{P-chart of Kegagalan Bahan Baku Jan - Mei 2018}

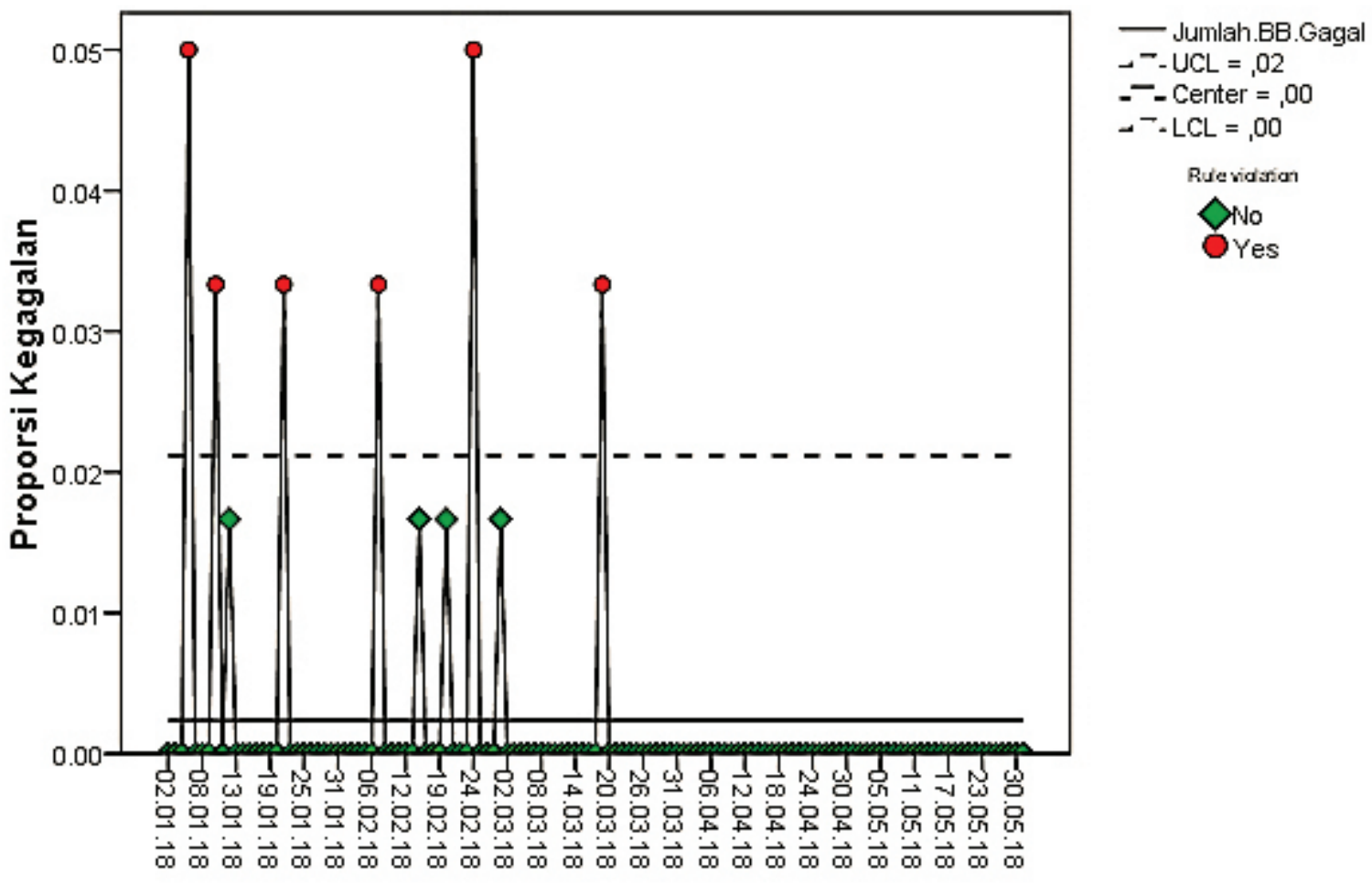

Sigma level: $\quad 3$

Gambar 3

P-chart Kegagalan Mutu Bahan Baku Utama Susu Kambing Bubuk Bumiku Hijau Januari - Mei 2018 Sumber: Data diolah primer, 2018

Hasil analisis peta kendali $P$ dengan batas kendali $3 \sigma$ diperoleh nilai $U C L(0,02), C L(0,00)$, dan $\operatorname{LCL}(0,00)$. Berdasarkan gambar 3 , dapat dilihat bahwa selama bulan Januari sampai dengan Maret 2018 proses tidak berada dalam pengendalian statistik karena terdapat enam titik yang melewati batas atas kendali statistik. Proporsi kegagalan mutu bahan baku tertinggi terjadi pada tanggal 3 Januari dan 24 Maret 2018 dengan jumlah susu kambing murni yang tidak lolos uji organoleptik sebanyak
3 liter. Susu kambing murni yang tidak lolos uji organoleptik tidak dikembalikan kepada peternak mitra, melainkan diletakkan di tempat khusus oleh staf penguji yang kemudian dibuang.

Susu kambing tersebut tidak dapat diproses lebih lanjut karena sudah tidak sesuai dengan standar mutu yang telah ditetapkan oleh Manajemen Bumiku Hijau. Susu kambing murni yang lolos uji organoleptik akan disimpan terlebih dahulu ke dalam freezer 
dengan suhu $70^{\circ} \mathrm{C}$ selama kurang lebih tiga hari. Berdasarkan hasil pengujian organoleptik susu kambing murni selama Januari sampai dengan Mei 2018, terdapat beberapa jenis penyebab kegagalan mutu bahan baku susu kambing murni di Bumiku Hijau Yogyakarta yang dapat dilihat pada gambar histogram gambar 4 .

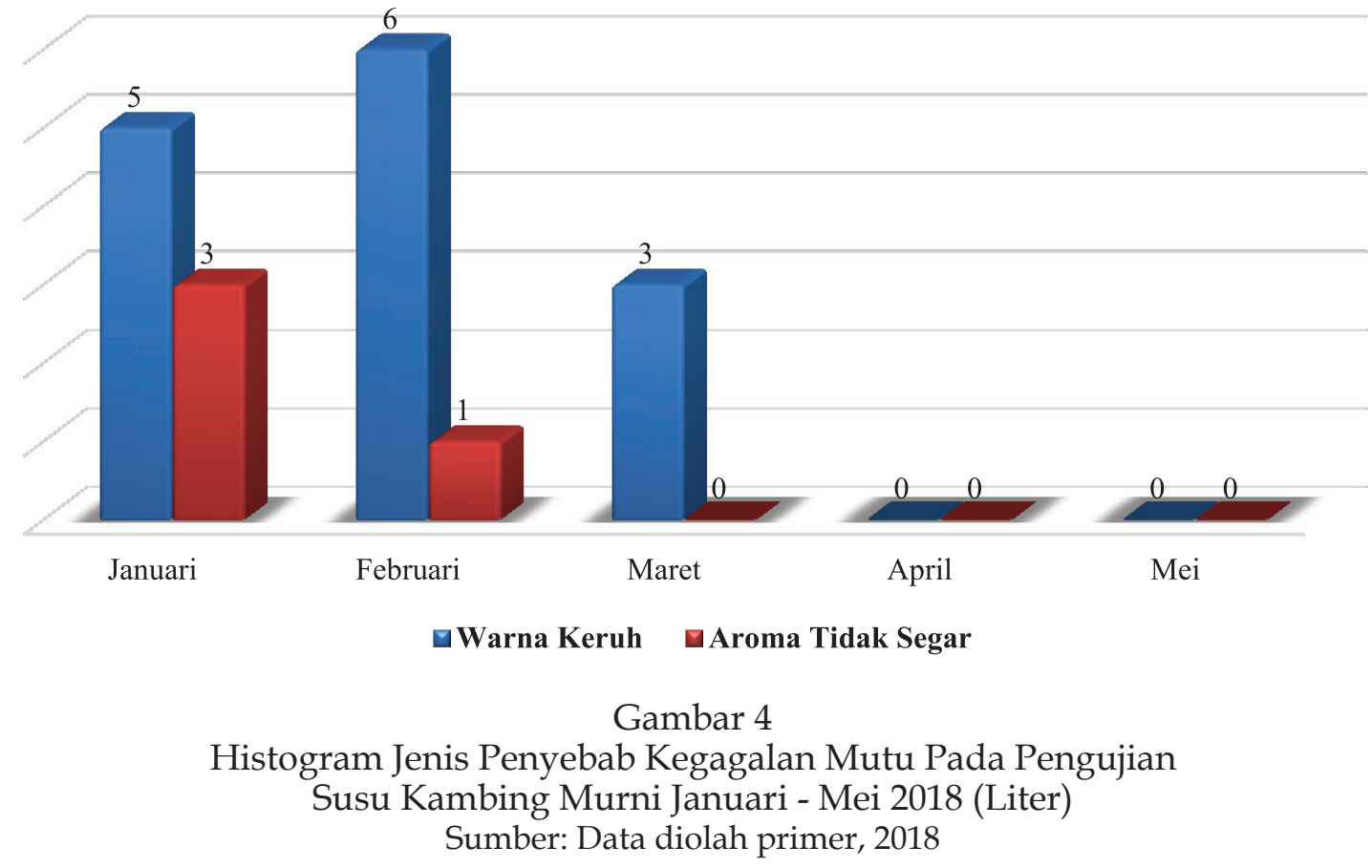

Jenis penyebab kegagalan dominan yang menyebabkan peta kendali atribut pada bahan baku berada di luar batas kendali statistik pada bulan Januari sampai dengan Maret 2018 adalah warna keruh, yaitu adanya kontaminasi hasil perahan susu kambing dengan sisa pakan kambing serta aroma susu kambing murni sudah tidak segar lagi (basi).

Pengujian mutu pada susu kambing murni secara organoleptik memiliki kelemahan berupa tingginya tingkat subyektivitas penguji, berbeda dengan penelitian pengendalian mutu pada susu sapi segar di CV Cita Nasional Getasan. Pengujian mutu pada susu sapi segar di CV Cita Nasional Getasan menggunakan beberapa pendekatan pengujian yang lebih terukur dan obyektif, antara lain melalui uji $\mathrm{pH}$, uji berat jenis, uji kadar lemak, uji kadar alkohol dan uji brix (Yuliyarto dkk., 2014). Uji brix dilakukan untuk mengetahui tingkat kemanisan sampel yang sedang diteliti, dimana pengujian tersebut dilakukan dengan menggunakan alat bantu berupa brix refraktometer. Satuan tingkat kemanisan dinyatakan dalam ${ }^{\circ}$ Brix (gram sukrosa/ 100 gram sampel). Nilai tingkat kemanisan suatu sampel yang tinggi menunjukkan semakin tinggi kandungan gulanya (Faradillah dkk., 2016).

\section{Identifikasi Faktor-Faktor Dominan Penyebab Kegagalan Bahan Baku Susu Kambing Murni Bumiku Hijau}

Dalam menggali informasi terkait faktorfaktor dominan penyebab kegagalan bahan baku utama pembuatan susu kambing murni Bumiku Hijau, perlu dilakukan analisis lebih lanjut dengan menggunakan diagram sebab - akibat (fishbone diagram). Diagram sebab akibat (fishbone diagram) merupakan alat untuk menganalisis proses bisnis dan efektivitasnya (Bose, 2012). Secara umum kerusakan disebabkan oleh lima faktor, yaitu man, material, machine, method, dan environment.

Berdasarkan hasil informasi yang didapat dan data kegagalan bahan baku utama di 
Bumiku Hijau yang telah dianalisis, maka prioritas permasalahan dan faktor-faktor penyebab kegagalan bahan baku dapat disusun ke dalam diagram sebab akibat (fishbone chart). Penyusunan diagram sebab akibat kegagalan bahan baku utama merupakan hasil pengamatan langsung di lapangan dan wawancara dengan pihak-pihak yang terkait, antara lain kepala bagian pengolahan dan penjualan susu kambing murni dan bubuk, staf bagian laboratorium penerimaan susu kambing murni, dan kepala bagian kandang. Beberapa penyebab kegagalan mutu susu kambing murni tersaji dalam diagram sebab akibat di bawah ini :

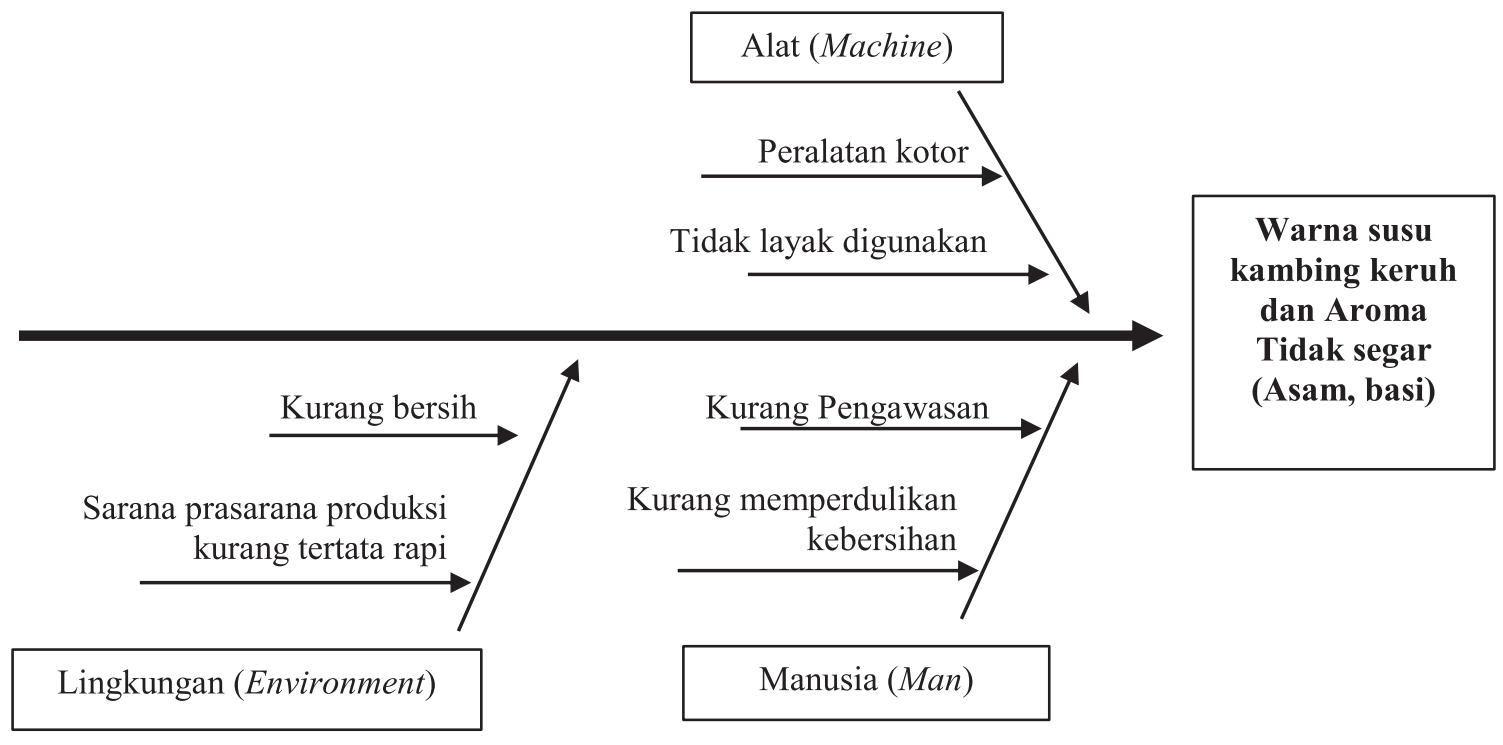

Gambar 5

Diagram Sebab - Akibat Warna Susu Kambing Murni Keruh dan Aroma Tidak Segar Sumber: Data diolah primer, 2018

Gambar 5 menunjukkan bahwa masalah kegagalan mutu pada susu kambing murni di Bumiku Hijau Yogyakarta disebabkan oleh tiga faktor utama, yaitu faktor manusia, alat produksi yang digunakan, dan lingkungan peternakan kambing perah peranakan etawa (mitra Bumiku Hijau). Faktor manusia (man), disebabkan karena kurangnya pengawasan pemilik peternakan kambing perah terhadap karyawannya. Karyawan di peternakan mitra Bumiku Hijau merupakan tenaga kerja terampil yang memahami teknik pemerahan susu kambing etawa. Meskipun termasuk tenaga kerja terampil, karyawan di peternakan mitra Bumiku Hijau kurang memperhatikan kebersihan alat produksi yang digunakan dan lingkungan kerja saat proses pemerahan susu kambing, sehingga hal tersebut berpengaruh pada kondisi fisik susu kambing yang disetorkan oleh peternak mitra ke Bumiku Hijau.

Faktor kedua yang menjadi penyebab kegagalan mutu susu kambing murni di Bumiku hijau adalah alat produksi yang digunakan. Beberapa alat produksi yang digunakan saat proses pemerahan susu kambing di peternakan mitra Bumiku Hijau antara lain seperti ember, tempat untuk memberi pakan kambing, dan tempat untuk menampung perahan susu kambing (drum stainless) sering kali tidak dicuci bersih. Sarana produksi tersebut dipakai setiap hari, akan tetapi sisa - sisa endapan susu kambing yang masih terdapat di dalam drum stainless berpengaruh pada kondisi fisik hasil perahan susu kambing berikutnya. Selain kendala sarana produksi yang kurang bersih, beberapa sarana produksi lainnya juga dalam kondisi yang sudah tidak layak pakai. Pihak peternakan mitra perlu melakukan pembaruan 
peralatan produksi, selain untuk mendukung kelancaran kinerja hal tersebut diharapkan mampu memotivasi karyawan untuk lebih memedulikan kebersihan alat produksi.

Faktor ketiga yang menyebabkan masalah kegagalan mutu susu kambing murni adalah lingkungan (environment) peternakan mitra Bumiku Hijau. Kondisi di dalam peternakan kambing mitra Bumiku Hijau terutama pada saat proses pemerahan susu kambing kurang bersih. Penataan peralatan produksi juga kurang tertata rapi, kedua hal tersebut apabila tidak dilakukan tindakan evaluasi dapat mencemari kondisi fisik hasil perahan susu kambing yang semula sudah sesuai dengan standar Bumiku Hijau menjadi tidak lolos uji karena warna susu menjadi keruh dan beraroma tidak segar (basi, asam).

Cyrilla dkk. (2015), menyatakan bahwa beberapa faktor penting yang mempengaruhi mutu susu kambing murni meliputi teknik penanganan hewan ternak, khususnya pada saat pemberian pakan, perlakuan pada hasil perahan susu kambing, proses pendinginan, pengangkutan, dan perawatan sarana prasarana produksi. Standar mutu susu kambing murni yang paling penting adalah rasa dan aroma yang mudah diterima serta menarik minat konsumen (Park, 2010).

Permasalahan kegagalan mutu pada susu kambing murni di Bumiku Hijau yang disebabkan oleh faktor manusia, alat produksi, dan lingkungan kerja peternakan mitra dapat diminimalisir dengan beberapa cara. Pihak manajemen Bumiku Hijau dapat bekerja sama dengan peternakan mitra untuk mengatasi masalah warna susu kambing yang keruh dan beraroma tidak segar, yaitu dengan cara memberikan penyuluhan dan pelatihan kepada karyawan pemerah susu kambing tentang teknik pemerahan susu kambing yang baik dan benar serta perlakuan pasca-proses pemerahan.

Pelaksanaan program penyuluhan dan pelatihan tersebut bertujuan untuk meminimalisir terjadinya pengulangan masalah pada mutu hasil perahan susu kambing murni, selain itu juga diharapkan mampu memotivasi peternakan mitra untuk konsisten dalam menjaga mutu susu kambing murni.
Selain pelaksanaan program penyuluhan dan pelatihan, Bumiku Hijau juga dapat menerapkan sistem reward and punishment kepada peternakan mitra usaha agar lebih terpacu dalam meningkatkan mutu hasil perahan susu kambing sebelum di suplai ke Bumiku Hijau.

Bumiku Hijau dapat memberikan reward berupa pembelian susu kambing segar lebih banyak dari yang telah diminta sebelumnya, atau penambahan insentif untuk peternakan mitra per bulannya. Sebaliknya, Bumiku Hijau dapat memberlakukan punishment kepada peternakan mitra apabila produk yang diminta tidak sesuai dengan standar perusahaan. Pemberlakuan punishment dapat berupa pengurangan permintaan produk dari yang telah disepakati sebelumnya, atau pemutusan kontrak kerja dengan peternakan mitra apabila mitra kerja tidak mampu memenuhi standar produk yang ditetapkan perusahaan dalam jangka waktu yang telah ditentukan.

\section{SIMPULAN}

Pengendalian mutu susu kambing murni yang dilakukan di Bumiku Hijau menggunakan peta kendali atribut $P$ masih belum optimal, karena grafik peta kendali menunjukkan selama bulan Januari sampai dengan Maret 2018 proses tidak berada dalam batas pengendalian statistik. Hasil identifikasi faktor - faktor penyebab kegagalan mutu bahan baku susu kambing bubuk di Bumiku Hijau menggunakan diagram sebab - akibat (fishbone diagram) meliputi faktor manusia (man), alat (machine), dan lingkungan (environment). Perusahaan bersama dengan peternakan mitra perlu melakukan pembinaan dan pelatihan untuk menumbuhkan rasa kepedulian kepada seluruh karyawan terhadap lingkungan kerja, peralatan produksi, dan bahan baku agar mutu produk yang dihasilkan tetap terjaga dengan baik.

Pada pembahasan telah dijelaskan bahwa pengujian mutu bahan baku secara organoleptik memiliki kelemahan berupa tingginya subjektifitas penguji, sehingga itu perlu dilakukan penelitian lebih lanjut terkait uji mutu bahan baku dengan pengujian yang 
lebih terukur. Parameter pengujian mutu bahan baku susu kambing bubuk dapat merujuk pada Standar Nasional Indonesia terkait syarat mutu susu segar di Indonesia, antara lain yaitu tingkat kadar lemak, uji cemaran mikroba, dan tingkat keasaman yang terkandung dalam susu.

\section{DAFTAR PUSTAKA}

Andarwati, Siti, Trisakti Haryadi, Budi Guntoro, Endang Sulastri, Raden Ahmad Romadhoni, Surya Putra, dan Gunawan. 2018. Relationship Between Farmer's Characteristics with the Motivation of Goat Milking in the Girikerto Village Turi District Sleman Regency. Bulletin of Animal Science, 42 (3) : 256 - 266.

Badan Standardisasi Nasional (BSN) Indonesia. 2011. Syarat Mutu Susu Segar. Jakarta : Badan Standardisasi Nasional (BSN) Indonesia.

Bose, Tarun Kanti. 2012. Application of Fishbone Analysis for Evaluating Supply Chain dan Business Process - A Case Study on the St. James Hospital. International Journal of Managing Value dan Supply Chains (IJMVSC), 3 (2) : 17-24.

Cyrilla. L, B. P. Purwanto, A. Atabany, D. A. Astuti, dan A. Sukmawati. 2015. Improving Milk Quality for Dairy Goat Farm Development. Media Peternakan, 38 (3) : 204-211.

Direktorat Jenderal Industri Agro, Kementerian Perindustrian Republik Indonesia. 2015. Pengembangan Industri Prioritas Agro. Jakarta : Kementerian Perindustrian Republik Indonesia.

Djekic, Ilija, Nada Smigic, Nikola Tomic, dan Danreja Rajkovic. 2014. Statistical Process Control In Serbian Food Packaging. International Journal for Quality Research, 8 (3) : 323 - 334.

Faradillah, Nida, Antonius Hintono, dan Yoyok Budi Pramono. 2016.
Karakteristik Permen Karamel Susu Rendah Kalori dengan Proporsi Sukrosa dan Gula Stevia (Stevia rebaudiana) yang Berbeda. Jurnal Aplikasi Teknologi Pangan, 6 (1) : 39 42.

Hariyanto, Mochammad Agus. 2017. Pengendalian Kualitas Produk Roti Tawar "Della" Menggunakan Metode Statistical Process Control. Simki - Economic, 1 (5) : 1 - 15.

Haryono, Didi dan Irwan. 2015. Pengendalian Kualitas Statistik (Pendekatan Teoritis dan Apilkatif). Bandung : Penerbit Alfabeta.

Jha, Mayank, R. K. Tyagi, dan G. Gupta. 2013. Reduction of Rejected Components In An Automobile Assembly Line Using Quality Tools. European Journal of Applied Engineering dan Scientific Research, 2 (3) : 13 - 17.

Kementerian Pertanian Indonesia. 2017. Outlook Susu 2017. Jakarta : Pusat Data dan Sistem Informasi, Pertanian dan Sekretaris Jenderal.

Miskiyah. 2011. Kajian Standar Nasional Indonesia Susu Cair Di Indonesia. Jurnal Standardisasi, 13 (1) : 1 - 7.

Montgomery, Douglas C. 2009. Introduction to Statistical Quality Control. Edisi Keenam, USA: John Wiley \& Sons, Inc.

Oguntunde, Pelumi, O. A. Odetunmibi, dan O. Ojo Oluwadare. 2015. A Comparative Study of the Use of Statistical Process Control in Monitoring Health Care Delivery. International Journal of Innovation dan Scientific Research (IJISR), 14 (2) : 154158.

Park, Young. 2010. Goat Milk Products: Quality, Composition, Processing, dan Marketing. 10.1081/E-EAS-120045703.

Tamime, A. Y. 2009. Milk Processing dan Quality Management. UK : Blackwell Publishing Ltd. 
Wasiksiri, Siriwat, Usa Chethanond, Sahutaya Pongprayoon, Somjit Srimai dan Bunjob Nasae. 2010. Quality Aspects of Raw Goat Milk in Lower Southern Thailand. Songklanakarin Journal Science Technology, 32 (2) : 109 - 113.

Yuliyarto, dan Yanuar Surya Putra. 2014. Analisis Quality Control Pada Produksi Susu Sapi di CV Cita Nasional Getasan. Among Makarti, 7 (14) : 79 - 91.
Zain, W. N. 2013. Kualitas Susu Kambing Segar Di Peternakan Umban Sari dan Alam Raya Kota Pekanbaru. Jurnal Peternakan, 10 (1) : 24 - 30.

Zare, Nima Mirzaei. 2016. Application of Statistical Process Control in Service Industry: A Case Study of the Restaurant Sector. Journal of Modelling in Management, 11 (3) :1 21. 